\title{
Sowjetisches Ehe- und Familienrecht von den Ersten Dekreten 1917 bis zum letzten Gesetzbuch 1968: vom Standpunkt der Lettischen Sozialistischen Sowjetrepublik
}

\author{
Sanita Osipova
}

Universität Lettlands
E-mail: sanita.osipova@lu.lv

\begin{abstract}
:
The Soviet law, which was created at the beginning of the 20th century in Soviet Russia, had evolved on the basis of the legal tradition of Continental Europe; it was a legal system based on the Marxist law theory as understood in Soviet Russia and later in the USSR and the countries that came under its influence. Marxism-Leninism maintained actual equality in society, including gender equality, which determined Soviet state policy in the sphere of marriage and family law. In the territories occupied by the USSR in 1940 - Latvia, Estonia, Lithuania - the previously existing national systems of law were replaced by Soviet law. As a result of the Soviet marriage and family regulations being put in place, the following was established in the territory of Latvia: civil marriage as the only valid form of marriage, equality of spouses, and the equality in the rights of all children regardless of whether they were born in or outside of marriage.
\end{abstract}

Keywords: Soviet marriage and family law; civil marriage; children rights; equality of spouses

DOI: $10.14712 / 2464689 X .2019 .7$

Im Sommer 1940 wurde die Republik Lettland von der Sowjetunion annektiert und in diese eingegliedert. Die Republik Lettland verlor ihre Unabhängigkeit und wurde zu einer der 15 Sowjetrepubliken. ${ }^{1}$ In den Gebieten, die nach dem Molotow-Ribbentrop-Pakt vom 21. August 1939 von der Sowjetunion besetzt wurden - Lettland, Estland, Litauen - wurden die bereits bestehenden nationalen Rechtssysteme durch das Sowjetrecht ersetzt, das auf der Ideologie des Marxismus-Leninismus beruhte. ${ }^{2}$ In den neuen Sowjetrepubliken

BLEIRE, D. - BUTULIS, I. - FELDMANIS, I. - STRANGA, A. - ZUNDA, A. Latvijas vēsture 20. gadsimts. 2. Aufl. Rīga: Jumava, 2005, s. 219-224.

2 BLŪZMA, V. Latvijas inkorporācija PSRS sastāvā un padomju tiesību uzspiešana Latvijai (1940-1941). In: LĒBERS D. A. (Hg.). Latvijas tiesību vēsture (1914-2000). Rīga: Fonds Latvijas Vēsture, 2000, s. 288-295. 
wurden die Gesetze Sowjetrusslands eingeführt, die in die jeweilige Landessprache jeder Republik übersetzt wurden. Dieser Prozess wurde rechtlich mit dem Dekret des Präsidiums des Obersten Sowjets der UdSSR „Über die vorläufige Anwendung des Straf-, Zivil- und Arbeitsrechts der RSFSR ${ }^{3}$ in den Gebieten der Litauischen, Lettischen und Estnischen Sozialistischen Sowjetrepubliken“" vom 6. November 1940 ins Leben gerufen. ${ }^{4}$

Das Aufzwingen des Sowjetrechts verursachte einen Abbruch des historischen Entwicklungsprozesses des Rechts in Lettland, weil das Recht einer anderen Nation und eines anderen Landes, dabei durch eine spezifische Ideologie geprägt, Lettland aufgezwungen wurde. Bevor man vom Familien- und Eherecht in der Lettischen SSR spricht, ist es notwendig, in einigen Worten die sowjetischen Gesetze zu beschreiben. Obwohl das Sowjetrecht, das Anfang des 20. Jh. laut der marxistischen Rechtstheorie in der Sowjetunion geschaffen wurde, auf der Grundlage der Rechtstradition Kontinentaleuropas entstand, unterschied es sich deutlich von der Rechtsauffassung des romanischen und germanischen Rechtskreises. ${ }^{5}$

Das sowjetische Ehe- und Familienrecht wurde noch nicht ausreichend gründlich in der Rechtswissenschaft Lettlands erforscht. Darum stützt sich diese wissenschaftliche Forschung grundsätzlich auf die Werke von Professors Janis Vebers (Jānis Vēbers, 1930-1997), die über das Ehe- und Familienrecht in Sowjetlettland noch zur Sowjetzeit verfasst wurden, ${ }^{6}$ auf einzelne, heutzutage veröffentlichte Beiträge des Professors und Rechtshistorikers Janis Lazdins (Jānis Lazdiņš, 1966) zu diesem Thema, ${ }^{7}$ sowie auf die unvollendete Dissertation der Doktorandin von Professor Lazdin Mg. iur. Ligita Pelmane über das Institut der elterlichen Gewalt in Lettland des 20. Jh., aus der ein Abschnitt in Form eines populär-wissenschaftlichen Artikels veröffentlicht wurde, ${ }^{8}$ sowie auf die Forschungen der heutigen russischen Wissenschaftler, weil die Entstehung und Entwicklung des Sowjetrechts im heutigen Russland im Gegensatz zu den baltischen Staaten sehr weitgehend untersucht wird, ${ }^{9}$ sowie auf die von der Autorin des Aufsatzes selbst durchgeführten Forschungen des Sowjetrechts.

3 Russische Sozialistische Föderative Sowjetrepublik.

$4 \quad$ VĒBERS, J. Gimenes tiesības. Rīga: P. Stučkas Latvijas Valsts Universitāte, 1970, S. 13.

5 Zum Beispiel, Notariat. AVENARIUS, M. Geschichte des Notariats in Russland. In: SCHOECKEL, M. SCHUBERT, W. (Hg.). Handbuch zur Geschichte des Notariats der europäischen Traditionen. BadenBaden: Nomos, 2009, S. 511-514.

6 VĒBERS, Gimenes tiesības. ВЕБЕРС, Я. Р. Правосубъектность граждан в советском гражданском и семейном праве. Рига: Зинатне, 1976. VĒBERS, J. - TORGĀNS, K. - ŠULCS, V. Padomju civiltiesības: mācību līdzeklis LPSR augstskolu studentiem. Bd. 2. Rīga: Zvaigzne, 1986, und VĒBERS, J. Latvijas PSR gimenes tiesības: mācību līdzeklis LPSR augstskolu studentiem. Rīga: Zvaigzne, 1984.

7 LAZDIN̦Š, J. Latvijas privāttiesības: raksti. Rīga: LU ž. "Latvijas Vēsture” fonds, 2003, S. 103, auch LAZDIN̦Š, J. Padomju tiesību periods Latvijā (1944/1945-1985). In: LĒBERS, D. A. (Hg.). Latvijas tiesību vēsture (1914-2000). Rīga: Fonds Latvijas Vēsture, 2000, S. 368-420.

8 PĒLMANE, L. Vecāku varas institūta transformācija vecāku aizgādības tiesībās. Jurista Vārds, 2010, Nr. 29. (624). [online]. [10. 8. 2018]. Verfügbar um: http://www.juristavards.lv.

9 Zum Beispiel, САРЫЧЕВА, Н. В. История становления института гражданского брака в России. [online]. [10. 8. 2018]. Verfügbar um: http://nina-saricheva.ru/stattya2.html, АНТИПОВА, Л. Коментарии к Декрету о расторжении брака, 16 (29) декабря 1917 г. [online]. [22. 2. 2019]. Verfügbar um:

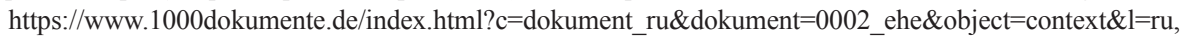
ПОЛЯНСКИЙ, П. Л. Реформирование советского семейного права в годы Великой Отечественной войны. [online]. [22. 2. 2019]. Verfügbar um: http://www.dissercat.com/content/reformirovanie-sovetskogo 


\section{Sowjetisches Recht: Richtlinien}

Die Erklärung der vom Staat genehmigten Rechtsvorschriften zur Hauptquelle des Rechts allein grenzte das Sowjetrecht von der romanisch-germanischen Rechtsfamilie nicht ab, in der Anfang des 20. Jh. der Rechtspositivismus gut bekannt war. ${ }^{10}$ Jedoch unterschied sich das auf die radikale marxistisch-leninistische Ideologie basierte Recht von der Rechtstradition Kontinentaleuropas dermaßen, dass das Sowjetrecht, oder wie es oft in der wissenschaftlichen Literatur bezeichnet wird, das sozialistische Recht einen eigenständigen Rechtsbereich in der Rechtsfamilie Kontinentaleuropas darstellte.

Welche Vorstellung der Sowjetstaat vom Recht hatte, veranschaulicht z.B. die Definition, die der Generalstaatsanwalt der UdSSR Andrei Wyschinski (Вышинский Андрей Януарьевич, 1883-1954) ${ }^{11}$ in seinem Vortrag bei der Beratung der ganzen Union über die Fragen zu sowjetischen Gesetzen und der Staatswissenschaft am 16. Juli 1938 anführte: „Das Recht bedeutet eine Gesamtheit von bestimmten Verhaltensregeln, die die Staatsgewalt durch den legislativen Prozess sanktioniert hat und die den Willen der herrschenden Klasse zum Ausdruck bringt; das ist die Gesamtheit von Gewohnheiten und Regeln des Zusammenlebens, deren Anwendung die Staatsgewalt zwangsweise gewährleistet, um eine für die herrschende Klasse vorteilhafte und erwünschte Ordnung sowie öffentliche Beziehungen zu schützen, zu stärken und zu entwickeln." ${ }^{12}$

Infolgedessen wurde das Privatrecht im sowjetischen Rechtssystem aufgehoben. Alle Rechtsverhältnisse wurden als öffentlich-rechtlich gestaltet. Das Sowjetrecht kennzeichneten folgende Merkmale:

1. Die Abschaffung des Privatbesitzes. Der Besitz natürlicher Personen wurde als persönliches Eigentum bezeichnet. Aus dem zivil-rechtlichen Verkehr wurden „Produktionsmittel" gezogen - Grundstücke, Werke, Fabriken, Wohnhäuser usw., nämlich das Eigentum, das seinem Besitzer Gewinn brachte. Z.B. besagte das ZGB der Lettischen SSR von 1964: „Im Besitz des Staates befinden sich Land, sein Untergrund, Gewässer, Wälder, Werke, Fabriken, Schächte, Erzminen, Elektrokraftwerke, Schienen-, Wasser-, Luft- und Autoverkehr, Banken, Kommunikationsmittel, staatlich organisierte Landwirtschafts-, Handels-, Kommunalunternehmen u.a. sowie Wohnungenfonds in Städten und Gemeinden. Das Land, sein Untergrund, die Gewässer und die Wälder, die das ausschließliche Eigentum des Staates darstellen, dürfen nur zur Nutzung gewährt werden." 13

2. Das Sowjetrecht entstand auf der Basis des Rechtspositivismus, der die europäische Rechtsphilosophie Ende des 19. Jh. - Anfang des 20. Jh. prägte. Als die einzigen sowjetischen Rechtsquellen wurden das Gesetz und die auf seiner Grundlage erlassenen Vorschriften anerkannt. Die Methoden der Rechtsauslegung wurden allein auf

-semeinogo-prava-v-gody-velikoi-otechestvennoi-voiny\#ixzz5gGWZdn4Т; ГОНГАЛО, Б. - КРАШЕННИНИКОВ, П. - МИХЕЕВА, Л. - РУЗАКОВА, О. Семейное право. Москва: Litres, 2018.

10 MEDER, S. Rechtsgeschichte. Köln - Weimar - Wien: Böhlau Verlag, 2005, S. 335, 336.

11 Вышинский Андрей Януарьевич. Министерство иностранных дел Российской Федерации. [online]. [22. 2. 2019]. Verfügbar um: http://www.mid.ru/about/professional_holiday/history//asset_publisher /8DMVoaXSrMPo/content/id/746553[skatīts.

12 ВЫШИНСКИЙ, А. Я. Вопросы теории и права. Москва: Госюриздат, 1949, S. 83.

13 VĒBERS, J. Latvijas PSR Civilkodeksa komentāri. Rīga: Liesma, 1979, S. 141. 
die grammatische Auslegung von Rechtsvorschriften beschränkt, damit man bei ihrer Anwendung den darin erfassten Willen des Gesetzgebers nicht verändern konnte. ${ }^{14}$

3. Der Marxismus-Leninismus trat für die faktische Gleichstellung in der Gesellschaft, darunter für die Gleichheit der Geschlechter ein, was die sowjetische Politik im Eheund Familienrecht bestimmte. Die Ehe wurde im „Manifest der Kommunistischen Partei“"von Karl Marx und Friedrich Engels ausdrücklich als ein Institut bezeichnet, das einem Mann-dem Ehemann - eine Frau-die Ehefrau - und den Eltern ihre Kinder auszubeuten erlaubte. Ein Zitat aus dem „Manifest der Kommunistischen Partei“: „Worauf beruht die gegenwärtige, die bürgerliche Familie? Auf dem Kapital, auf dem Privaterwerb... Aber ihr, Kommunisten wollt die Weibergemeinschaft einführen, schreit uns die ganze Bourgeoisie im Chor entgegen. Der Bourgeois sieht in seiner Frau ein bloßes Produktionsinstrument. Er hört, dass die Produktionsinstrumente gemeinschaftlich ausgebeutet werden sollen, und kann sich natürlich nichts anderes denken, als dass das Los der Gemeinschaftlichkeit die Weiber gleichfalls treffen wird." 15 Außerdem glaubte Friedrich Engels ursprünglich an die „Utopie“, dass die Ehe und die Familie in der kommunistischen Gesellschaft von Gleichberechtigten mit der Zeit verschwinden werden. Später überarbeiteten die Marxismus-Klassiker diese Idee in dem Sinne, dass sich nur der Charakter der Familie ändern sollte. ${ }^{16}$ Sie werde zu einem Bund zweier freier und gleichberechtigter Personen, gestützt auf Liebe und gegenseitigen Respekt. ${ }^{17}$ Aus diesem Grund wurden im Sowjetstaat der Charakter und die soziale Bedeutung der Ehe und der Familie überprüft, und ein der Ideologie entsprechendes Recht entwickelt.

Auf solche Art und Weise bildete sich ein ganz neuer, sowjetischer Rechtskreis heraus, unabhängig davon, dass das Sowjetrecht auf der Grundlage der in Jahrhunderten gereiften Ideale der Rechtsphilosophie des christlichen Europas sowie auf der Basis der kontinentaleuropäischen Rechtstradition entstand. Dieser wurde von der engen, dogmatischen Richtung der sozialistischen Rechtsphilosophie des Marxismus-Leninismus, die zur nationalen Ideologie verkündet wurde, sowie von den auf ihrer Grundlage durchgeführten grundlegenden Transformationen der rechtlichen Verhältnisse geprägt. ${ }^{18} \mathrm{Zu}$ der Zeit, als die Gesetze der RSFSR im Jahre 1940 in der Lettischen SSR in Kraft traten, hatte das Sowjetrecht in Russland die Entstehung und einen wesentlichen evolutionären Weg bereits hinter sich. Dies bedeutete, dass Lettland die Experimente ergespart blieben, die Sowjetrussland bei der Gestaltung der sowjetischen Ehe gemacht hatte.

14 НЕДБАЙЛО, П. Е. Применение советских правовых норм. Москва: Госюриздат, 1960, S. 584, auch ЛАЗАРЕВ, В. В. Применение советского права. Казань: Изд. Казанского Университета, 1972, S. 32.

15 MARX, K. - ENGELS, F. Das Manifest der Kommunistische Partei. Zittau: Berndt Müller Verlag, 2009, S. 45.

16 HENNINGS, L. Marx, Engels und die Teilung der Arbeit: ein einführendes Lesebuch in Gesellschaftstheorie und Geschichte. 8. Aufl. Berlin: Grin Verlag, 2012, S. 294.

17 АНТИПОВА, op. cit.

18 LAZDIN̦Š, J. - OSIPOVA, S. Latvijas tiesību sistēmas ǵenēzes un evolūcijas aspekti Eiropas tiesību kontekstā. In: Tiesību harmonizācija Baltijas jūras reǵionā pēc ES paplašināšanās. Rīga: LU Akadēmiskais apgāds, 2012, S. 324, 325. 


\section{Vorgeschichte des sowjetischen Ehe- und Familienrechts zwischen 1917 und 1926 - ,Liberale“ Phase}

Bereits kurz nach der bolschewistischen Revolution am 7. November 1917 begann die neue Regierung in Russland mit Änderungen des Ehe- und Familienrechts. Bis dahin wurde das Eherecht in Russland vom Kirchenrecht, während das Familienrecht vom lokalen Zivilrecht und Gewohnheitsrecht geregelt. Die Gutsherren und die städtischen Familien lebten nach dem Kirchen- und Zivilrecht, die Bauern aber - nach dem Kirchen - und Gewohnheitsrecht. Darüber hinaus legte das weite Reich mit verschiedenen ethnischen und religiösen Gruppen fest, dass in verschiedenen Regionen unterschiedliche zivilrechtliche Normen galten. Die Ostseegouvernements hatten ihr eigenes Zivilrecht, ${ }^{19}$ Finnland, Polen und andere Gebiete verfügten ebenfalls über eine gewisse Rechtsautonomie. ${ }^{20}$

Seit der 2. Hälfte des 19. Jh. war die Ehescheidung das meist aktualisierte Thema des Eherechts im Russischen Reich. Obwohl die Scheidung im zaristischen Russland zugelassen war, fiel diese samt der Eheschließung in die Zuständigkeit der Kirche. Das kirchliche Scheidungsverfahren war lang und kompliziert. Die Ehescheidung war nur in den vom Gesetz besonders festgelegten Ausnahmefällen erlaubt. Solche Fälle waren z.B. eine mindestens 3 Jahre andauernde Impotenz des Ehemannes, der Ehebruch oder der Beitritt eines der Ehepartner einem Kloster. Die Ehescheidung war im Russischen Reich eine außerordentliche Maßnahme, denn noch zu Beginn des 20. Jh. wurden pro Jahr nur 0,029 Ehen pro 1000 Personen geschieden. ${ }^{21}$ Für die Liberalisierung der Ehescheidung setzten sich sowohl die Liberalen, die sich für die Personenfreiheit engagierten, als auch die Sozialdemokraten, die glaubten, dass das bestehende Recht die Frau diskriminiert und sie zum Eigentum des Mannes und zum Ausbeutungsobjekt macht, erfolglos ein. Nach Ansicht der Sozialisten war die Scheidung als Beendigung der Macht des Mannes über die Frau eine Voraussetzung für die Frauenemanzipation. ${ }^{22}$ Dies stand im Gegensatz zur Politik des Reiches, da eine monogame, stabile Familie, die in sich auch eine wirtschaftliche Einheit darstellte, als ein wichtiger, konstanter Wert galt, sodass das Scheidungsverfahren nicht leichter gemacht wurde.

Als die Linke an die Macht kam, entfach in Sowjetrussland eine breite Diskussion darüber, ob die Ehe und die Familie in der neuen Gesellschaft, die sich frei entwickeln sollte, überhaupt notwendig sind. Es wurden Ideen über freie sexuelle Beziehungen zwischen den Geschlechtern. Die meisten Revolutionäre setzten sich jedoch für eine zumindest vorübergehende Beibehaltung der Institution der Ehe ein, gewiss passten sie diese wesentlich an die neuen Ideale an. ${ }^{23}$ Es wurde nämlich das Ziel gesetzt, die Familie als einen vom wirtschaftlichen Interesse freien Bund gleichberechtigter Ehepartner zu bilden. ${ }^{24}$ Die Ent-

19 Свод гражданских узаконений губерний Прибалтийских.Часть III Свода местных узаконений губерний Остзейских. Петроград: Право, 1915, und LUTS, M. Aktuelle Zivilrechtsreform in Estland als eine historische Herausforederung. In: HEISS, H. (Hg.) Zivilrechtsreform im Baltikum. Studien zum ausländischen und internationalen Privatrecht. Bd. 161. Tübingen: Mohr Siebeck, 2006, S. 31, 32. ПАХМАН, С. В. История кодификации гражданского права. Москва: Зерцало, 2004, S. 399.

21 МИРОНОВ, Б. Н. Социальная история России периода империи (ХVIII - начало ХХ вв.): генезис личности, демократической семьи, гражданского общества и правового государства. Вd. 1. СанктПетербург: Дм. Буланин, 1999, S. 176.

22 АНТИПОВА, op. cit.

23 KÖNIG, R. Familiensoziologie. Berlin - Heidelberg: Springer-Verlag, 2013, S. 140, 141.

24 FALLE, F. W. Die Frau in Sowjetrussland. P. Zsolnay, 1932, S. 155. 
wicklung des sowjetischen Familienrechts leiteten zwei von Lenin unterzeichnete Dekrete des Allrussischen Zentralen Exekutivkomitees und des Rates der Volkskommissare der RSFSR ein, mit denen die Familienrechtspolitik des neuen Sowjetstaates verkündet wurde. Diese Politik zielte auf ,die Abschaffung der Versklavung von Frauen, die Befreiung der Familie von feudalen Überresten und der Ungleichheit" 25 gerichtet.

$\mathrm{Da}$ auch Lenin die bürgerliche Familie als Institut der Unterjochung von Frauen betrachtete, war die erste Rechtsvorschrift des sowjetischen Eherechts das Dekret „Über die Ehescheidung“ vom 16. (29.) Dezember 1917, das die Zuständigkeit der Kirche in Sachen Ehescheidung durch die staatliche Zuständigkeit ersetzt wurde. Die Behörden, die gemäß dem Dekret eine Ehe scheiden durften, waren lokale sowjetische Gerichte und Standesämter. Um einen Antrag auf die Ehescheidung zu stellen, musste die Person weder einen Grund für die Scheidung angeben, noch Beweise anführen. Der Richter hörte sich bei der Verhandlung beide Ehegatten an. Es genügte des Wunsches nach Ehescheidung nur eines der Ehegatten, um dieser Forderung Folge zu leisten. Für die Ehescheidung durch das Standesamt bedurfte es der Zustimmung beider Ehegatten. ${ }^{26}$ Somit wurde in Sowjetrussland eine freie Ehescheidung eingeführt, die auf dem Grundsatz der Gleichberechtigung beider Ehepartner beruhte. ${ }^{27}$ Die ursprüngliche Auffassung der Ehescheidung war im Sowjetrecht wegen ihres Liberalismus revolutionär. Später wurde diese wesentlich überarbeitet.

Am 18. (31.) Dezember 1917 wurde das Dekret „Über die Zivilehe, Kinder und die Einführung von Personenstandbüchern“ verabschiedet, ${ }^{28}$ mit dem der Staat die kirchliche Ehe als eine offizielle Form der Eheschließung aufhob und das Recht der Kirche, Personenstandbücher zu führen, übernahm. Die Ehe vom Gottessegen wurde in einen zivilrechtlichen Vertrag transformiert. ${ }^{29}$ Das war zu Beginn des 20. Jh. kein revolutionärer Schritt, da die Trennung von Staat und Kirche in Europa keine Innovation war. Bereits Ende des 18. Jh. wurden in Frankreich Grundlagen der Zivilehe als einzige rechtmäßige Form der Eheschließung geschaffen. Das erwähnte Dekret definierte die Familie als einen monogamen, frei gebildeten Bund absolut gleichberechtigter Partner und führte die Gütertrennung der Ehegatten ein, um die wirtschaftliche Abhängigkeit der Frau von ihrem Mann aufzuheben. Früher wurde der Mann durch die Eheschließung zum Vormund seiner Frau und verwaltete ihr Eigentum. Das Dekret betonte die Gleichstellung beider Ehegatten bezüglich der Personen- und Vermögensverhältnisse. ${ }^{30}$ Gleichzeitig wurden uneheliche Kinder den ehelichen gleichgestellt. Es ist festzustellen, dass das Konzept des Sowjetrechts in Europa revolutionär war, da der konservative Teil Europas zu solchen rechtlichen Lösungen erst in der 2. Hälfte des 20. Jh. kam.

25

Декрет о расторжении брака, 16 (29) декабьря 1917 г. In: Декреть Советской власти. Москва: Directmedia, 2016, S. 237, 238.

27 VĒBERS, Gimenes tiesības, S. 13.

28 Декрет ВЦИК и СНК о гражданском браке, о детях и о ведении книг актов состояния 18(31) декабря 1917 г. In: Декреты Советской власти. Москва: Directmedia, 2016, S. 247-249.

29 МАКЕДОНСКАЯ, В. А. - ШВЕЦ, Т. Д. Семейные ценности и брак: история и современные реалии. Образование личности, 2015, Bd. 1, S. 70, 71.

30 VËBERS, Gimenes tiesības, S. 13. 
Hier ist noch eine Maßnahme der Sowjetmacht zum Schutz von Fraueninteressen zu erwähnen, obwohl sie nicht ganz als eine Regelung des Familienrechtes zu betrachten ist das Dekret „Über den Gesundheitsschutz von Frauen“ vom 18. November 1920, mit dem das Recht von Frauen auf eine Abtreibung zum ersten Mal in der Welt legalisiert wurde. Laut dem Dekret konnte eine Abtreibung kostenlos in einem staatlichen Krankenhaus von einem Arzt durchgeführt werden. ${ }^{31}$ Der Sowjetstaat unterstützte zwar prinzipiell keine Abtreibungen, aber dieses Dekret bekämpfte illegale Abtreibungen, die die Gesundheit und das Leben von Frauen gefährdeten.

Der Staat und die Kirche wurden in Sowjetrussland mit dem Dekret vom 2. Februar 1918 vollständig voneinander getrennt. ${ }^{32}$ Obwohl das Dekret die Religionsfreiheit verkündete, schränkte es die Rechte von Gläubigen ein, später folgte sogar eine offene Verfolgung von Gläubigen.

Am 16. September 1918 wurde das erste sowjetrussische Gesetzbuch über die Personenstandbücher und das Ehe-, Familien- und Vormundschaftsrecht verabschiedet. ${ }^{33}$ Dies bestätigte, dass das Sowjetrecht die bereichsbezogene kontinentaleuropäische Tradition der Rechtskodifizierung verfolgte. Neu war die Tatsache, dass das Ehe- und Familienrecht vom Zivilrecht als selbstständiger Rechtsbereich ausgegliedert wurde. Damit wurde demonstriert, dass das sowjetische Familienrecht nicht auf wirtschaftlichen Interessen beruhte, die durch das Zivilrecht geregelt und geschützt wurden.

Das Gesetzbuch setzte die bereits durch die Dekrete etablierte Tradition der Gleichstellung von Ehegatten fort. Es legte fest, dass die Ehe aus freiem Willen beider Partner geschlossen wird. Die Voraussetzungen für die Eheschließung waren das Alterszensus, d.h. heiraten durften Personen ab bestimmtem Alter: Frauen ab 16 Jahren, Männer ab 18 Jahren, sowie andere Zensus: vollmündige Personen, unverheiratete Personen, keine nahen Blutverwandten der potenziellen Ehegatten - Vorfahren, Nachfahren sowie Geschwister, Stiefbrüder, Stiefschwestern. ${ }^{34}$ Diesbezüglich unterschieden sich die Anforderungen der sowjetischen Gesetze nicht von den europäischen Rechtstraditionen.

Die Neuerungen befanden sich in den Artikeln, die die früheren Beschränkungen für eine Eheschließung enthielten. Die Artikel 71 bis 73 erlaubten neuerdings die Heirat von Angehörigen unterschiedlicher Konfessionen sowie die Heirat von Mönchen, Geistlichen und Personen, die das Zölibat geschworen hatten. Nur ein Gericht konnte eine Ehe für nichtig erklären. ${ }^{35}$ Die Regelung der Ehescheidung wurde von dem Dekret übernommen. Das Gesetzbuch sah auch eine Unterhaltsverpflichtung vor. Nach der Eheschließung mussten die Ehegatten einen gemeinsamen Familiennamen führen, sie konnten sich aber sowohl

31 Постановление Наркомздрава РСФСР, Наркомюста РСФСР от 18. 11. 1920 “Об охране здоровья женщин”. [online]. [20. 2. 2019]. Verfügbar um: https://ipravo.info/sssr1/laws96/770.htm.

32 Декрет Советом Народных Комиссаров РСФСР 23 об отделении церкви от государства и школы от церкви принятый января 1918 года. In: Свод законов РСФСР. Bd. 1. Москва: Сов. Россия, 1988, S. 861.

33 Кодексс законов об актах гражданского состояния, брачном, семейном и опекунском праве (принят 16. 9. 1918). In: Собрание узаконений и распоряжений правительства за 1917-1918 г2. Управление делами Совнаркома СССР. Москва: Управление делами Совнаркома СССР, 1942, S. 1045-1074.

34 Ibidem.

35 Ibidem. 
für den Nachnamen des Mannes als auch den der Frau frei entscheiden (Art. 100). ${ }^{36}$ Ebenfalls hatten die Ehegatten das Recht, ihren Wohnort zu wählen, und sie mussten nicht unbedingt einen gemeinsamen Wohnort haben (Art. 104). Es bestand eine Gütergemeinschaft weder zwischen den Ehegatten (Art. 105) noch zwischen den Eltern und den Kindern. Es wurde festgelegt, dass die Kinder keinen Anspruch auf das Vermögen der Eltern hatten, und umgekehrt hatten sie keinen Anspruch auf das Vermögen der Kinder. Die Eltern waren ihren minderjährigen und arbeitsunfähigen Kindern unterhaltspflichtig (Art. 160, 161). Die Unterhaltspflicht der Eltern gegenüber den Kindern erlosch aber, wenn die Kinder vom Staat versorgt wurden. Teilweise sollten auch utopische sozialistische Ideale verwirklicht werden, laut denen für die Erziehung der jungen Generation die ganze Gesellschaft verantwortlich war.

Im Gesetzbuch galt als Grundlage für die Verwandtschaft die tatsächliche (biologische) Herkunft, und für alle Kinder wurde der Grundsatz der Gleichstellung festgelegt, d.h. uneheliche Kinder wurden den ehelichen gleichgestellt. ${ }^{37}$ Das Gesetzbuch legte auch fest, dass die bis zu seinem Inkrafttreten adoptierten oder in die Erziehung genommenen Kinder den biologischen Kindern gleichgestellt waren, jedoch wurde die Adoption von Kindern in Sowjetrussland verboten. Das Adoptionsverbot beruhte auf der Überzeugung, der Sowjetstaat würde sich um alle Kinder, die aus irgendeinem Grund ohne Eltern blieben, kümmern. ${ }^{38}$ Auch in diesen Rechtsvorschriften fanden die Ideen einer ideellen Zukunftsgesellschaft Niederschlag, in der der Staat oder die ganze Gesellschaft für die Kinder sorgen.

Während in den Dekreten und im Gesetzbuch von 1918 der Begriff „Zivilehe“ als Gegensatz zur „Kirchenehe“ verwendet wurde, erschien er in späteren Rechtsvorschriften nicht mehr. Die späteren Rechtsvorschriften verwendeten die Begriffe „Ehe“ und „Faktische Ehe“. ${ }^{39}$ Außerdem wurde im Gesetzbuch der RSFSR „Über die Ehe, Familie und Vormundschaft" vom 19. November 1926 ein völlig neuer juristischer Begriff eingeführt - „die faktischen ehelichen Beziehungen“, unter denen man ein nicht faktisches Zusammenleben von Personen verstand, das in seinen juristischen Auswirkungen, d.h. den gegenseitigen Rechten und Pflichten der Beteiligten einer unverheirateten oder sogenannten „Faktischen Ehe“ gleichgestellt war. ${ }^{40}$

Der Legalisierung des faktischen Zusammenlebens lag die Tatsache zugrunde, dass es im neuen Sowjetstaat viele Paare gab, die während des Bürgerkriegs oder später ihr Zusammenleben nicht legalisiert hatten. Bei der Volkszählung 1923 wurden in Sowjetrussland ca. 100000 unverheiratete Paare festgestellt, die seit langem zusammen lebten und Kinder

36 Кодексс законов об актах гражданского состояния, брачном, семейном и опекунском праве (принят 16. 9. 1918).

37 ВЕБЕРС, Я. Р. Родство как основание возникновенияправ и обязанностей по советскоку семейному и гражданскому праву. Автореферат диссертации на соискание учёной степени кандидата юридических наук. Москва: Московский Государственный Университет им. В. И. Ленина, 1963, S. 3.

38 НОВИЦКИЙ, И. Б. История советского гражданского права. Москва: Госюриздат, 1957, S. 89.

39 САРЫЧЕВА, История становления института гражданского брака в России, und Декрет о расторжении брака, 16 (29) декабря 1917 г.

40 Кодекс законов о браке, семье и опеке РСФСР 1926 года. In: Собрание Узаконнений РСФСР, 1926, Bd. 82, s. 612, analisiert zum Beispiel in: ДОРСКАЯ, А. А. Кодексс законов о браке и семье и опеке РСФСР 1926 г.: соотношение идеологической и юридической составляющих. Universum Iuris. 2016, Nr. 2. [online]. [20. 2. 2019]. Verfügbar um: http://www.universum-juris.org/?q=ru/node/25. 
großzogen. ${ }^{41}$ Das ist ein ganz aktuelles Problem, weil derzeit in den meisten europäischen Ländern bis zur Hälfte der Neugeborenen von Personen stammen, die ihre Partnerschaft nicht legalisiert haben. ${ }^{42}$ Die sowjetische Gesetzgebung reagierte Anfang des 20. Jh. auf diese soziale Tendenz so, das es das Konzept der „faktischen Ehe“ einführte. Art. 3 des Gesetzbuchs „Über die Ehe, Familie und Vormundschaft“ legte fest, dass Paare, die ihre Partnerschaft nicht legalisiert hatten, jederzeit berechtigt waren, das Zusammenleben und dabei das Datum seines Anfangs beim Standesamt registrieren zu lassen. Interessant war, dass auch die „faktische Ehe“ durch das Gericht geschieden werden durfte. Das Gericht sollte in der Verhandlung zuerst feststellen, ob das faktischen Zusammenleben, dessen Merkmale in Art. 12 des Gesetzbuchs festgelegt waren, tatsächlich bestand: „Ein gemeinsamer Wohnort, ein gemeinsamer Haushalt und die Bestätigung gegenseitiger Beziehungen der Ehegatten in persönlicher Korrespondenz an Dritte oder in anderen Dokumenten sowie die von den Umständen abhängige gemeinsame materielle Unterstützung, die gemeinsame Erziehung von Kindern und andere Umstände. “43 Mit der Einführung der „faktischen Ehe“ vereinfachte die Gesetzgebung gleichzeitig das Ehescheidungsverfahren. Art. 19 des Gesetzbuchs legte fest, dass die Ehescheidung, das Sorgerecht über die gemeinsamen Kinder sowie die Unterhaltspflicht in die Personenstandbücher beim Standesamt einzutragen sind. Das Gericht war aber nicht berechtigt, die Ehe zu scheiden. ${ }^{44}$ Später, als der Sowjetstaat beschloss, dass die Ehe ein Wert ist, wurde dieser liberale Ansatz der Ehescheidung in der Doktrin des sowjetischen Familienrechts ausdrücklich kritisiert, weil ,dies die Rolle des Familienrechts bei der Bildung neuer Familienverhältnisse in der Praxis verringerte und bei einigen weniger gewissenhaften Bürgern eine nicht ernsthafte Haltung gegenüber der Ehe und Familie erweckte. “45

Häufig gingen Personen aus einer „Faktischen“ Partnerschaft nach dem Tode ihres „,faktischen Ehegatten“ vors Gericht, um ihre Erbansprüche geltend zu machen, da ein Notar gemäß der Notargesetze den faktischen Ehegatten als Erben nicht anerkennen konnte. ${ }^{46}$ Dies alles machte noch die Tatsache komplizierter, dass die sowjetische Gesetzgebung bei der Überarbeitung des Gesetzbuchs von 1926 die Gütertrennung durch die Gütergemeinschaft ersetzte. Es stellte sich heraus, dass die Gütertrennung aus materieller Sicht gerade nicht erwerbstätige Frauen gefährdete, die den Haushalt führten und Kinder großzogen, und nach der Ehescheidung ohne Lebensunterhalt blieben. Darüber hinaus stellte der Sowjetstaat fest, dass die liberale Ehe in ländlichen Gebieten zur Frauenausbeutung missbraucht wurde. Die Bauern heirateten oft eine Frau nur für eine Saison, d. h. für den Sommer oder die Erntezeit. Als die Arbeit erledigt war, ließen sie sich von der Frau scheiden und schickten sie mittellos aus dem Haus. ${ }^{47}$ Dabei machten sie von einer schnellen und billigen Eheschließung und Ehescheidung sowie dem Grundsatz der Gütertrennung

41 САРЫЧЕВА, История становления института гражданского брака в России.

42 Zum Beispiel in Deutschland, Kind ohne Trauschein: Welche Dokumente Väter benötigen. Berlin.de. Das offizielle Haupstadtportal. [online]. [28. 9. 2018]. Verfügbar um: https://www.berlin.de/special/familien /2901458-2864562-kind-ohne-trauschein-welche-dokumente-va.html.

43 Кодекс законов о браке, семье и опеке РСФСР 1926 года.

44 Ibidem.

45 VĒBERS, Gimenes tiesības, S. 15.

46 САРЫЧЕВА, История становления института гражданского брака в России.

47 Ibidem. 
Gebrauch. Das sowjetische Familienrechts betonte, dass die durch das Gesetzbuch von 1926 erfolgten Änderungen zum Schutz der Interessen von Frauen und minderjährigen Kindern getroffen wurden, wobei die Rolle der Familie gestärkt, jedoch die Rolle und Pflichten der Gesellschaft in ehelichen und Familienverhältnissen vermindert wurden. ${ }^{48}$ Dies belegten die neuen Grundsätze für die Definierung von Verwandtschaft. Vorher waren die biologische Herkunft oder Blutverwandtschaft für die Bestimmung der Verwandtschaft ausschlaggebend, was weitgehend durch die Ehe der Eltern bestätigt wurde, d. h., durch die Annahme, dass der Ehemann der Mutter auch der Kindesvater war. Im Gegensatz dazu erlaubte das Gesetz von 1926 dem Mann, seine Vaterschaft unabhängig von der Tatsache der Heirat mit der Mutter des Kindes anzumelden. Wichtig war nur, dass eine Person ein Kind als ihr eigenes anerkannt und der Staat dies eingetragen hatt. Der Staat setzte voraus, dass der biologische Vater die Vaterschaft anerkennt, aber in der Praxis war dies nicht immer der Fall. Wenn der Vater das Kind nicht anerkennen wollte, gab es im Gesetzbuch die Möglichkeit, die Vaterschaft durch das Gericht feststellen zu lassen. Die Verwandtschaft wurde in erster Linie als eine soziale, nicht als biologische Verbindung zwischen den Eltern und Kindern betrachtet. ${ }^{49}$ Es ist festzuhalten, dass es zu jenem Zeitpunkt viele Kinder gab, deren Vaterschaft überhaupt nicht registriert wurde.

Ferner wurde wieder das Institut der Adoption eingeführt, so dass nur Minderjährige und Nicht-Volljährige adoptiert werden konnten. Adoptiveltern oder Vormund durften keine Personen werden, die ihren Lebensunterhalt in Diensten eines religiösen Kults verdienten, Personen, die im zaristischen Russland im Polizeisystem tätig waren, Angehörige des russischen Kaiserhauses, geistig kranke und demente Personen sowie diejenigen, die wegen Straftaten aus Habgier und wegen Verführung zur Unzucht verurteilt worden waren. Diese Regelung wurde weitgehend von den in Artikel 69 der Verfassung der RSSR von 1925 festgelegten Einschränkungen des aktiven und passiven Wahlrechts für die vorher erwähnten Personen und noch andere Personengruppen (Personen, die Arbeitskräfte beschäftigen, Personen, die von Kapital-, Mietzinsen u.ä. lebten, private Händler und Makler) übernommen. 50

Mit der Verabschiedung und dem Inkrafttreten des Gesetzbuchs von 1926 endete die liberale Phase des sowjetischen Ehe- und Familienrechts, die in der sowjetischen Doktrin als Phase des Aufbaus des Sozialismus bezeichnet wurde.

In dieser Hinsicht war das Sowjetrecht in seiner Zeit fortschrittlich und zeichnete sich durch Lösungen aus, die im restlichen Europa erst in der 2. Hälfte oder sogar Ende des 20. Jh. erschienen. Zugleich muss man darauf hinweisen, dass dieses Recht und diese Freiheiten nicht für alle Mitglieder der Gesellschaft galten. Ein Teil der Gesellschaft, zum Beispiel Adelige und Geistliche des ehemaligen russischen Reiches sowie Händler und Makler waren in ihren politischen und bürgerlichen Rechten eingeschränkt, z.B. Kinder zu adoptieren oder die Vormundschaft zu beantragen. Die Gleichstellung betraf nur die Arbeiter: das Proletariat, die Bauern und teilweise auch die Intellektuellen (nach dem

48 VĒBERS, Gimenes tiesības, S. 15.

49 ВЕБЕРС, Родство как основание возникновенияправ и обязанностей по советскоку семейному и гражданскому праву, S. 3.

50 Постановление XII Всероссийского Съезда Советов от 11 мая 1925 года «Об Утверждении Конституции (Основного Закона) РСФСР». In: Собрание узаконений и распоряжений Рабочекрестьянского Правительства РСФСР, 1925, Bd. 30, S. 218. 
sowjetischen Konzept verstand man unter der Intelligenz Bedienstete, da ihre Aufgabe war es, dem arbeitenden Volk mit ihren Diensten, z.B. als Arzt, Lehrer, Bibliothekar oder mit ihrer kreativen Tätigkeit als Künstler, Schriftsteller, Musiker) zu dienen, falls ihre Ansichten und kreative Tätigkeit nicht als anti-staatlich angesehen wurden. Viele Intellektuelle hatten das Land als Dissidenten verlassen, aber das ist schon Gegenstand einer anderen Studie. ${ }^{51}$

\section{Entwicklung des sowjetischen Ehe- und Familienrechts unter Stalin 1926-1953}

Gleichzeitig mit der Stärkung der Macht Stalins bei der Schaffung eines totalitären Staates und mit dem Beginn des Terrors machte sich eine Änderung der sowjetischen Politik bemerkbar: die Bürgerrechte und Freiheiten wurden drastisch eingeschränkt. Der Staat übernahm eine immer größere Verantwortung für das Leben von Menschen, was eine strenge Regelung der sozialen Beziehungen und umfangreichere Verbote zur Folge hatte. ${ }^{52}$ Juristisch wichtig war die Verfassung von 1936, mit der sich der sowjetische Staat verpflichtete, seinen Bürgern ein breites Spektrum von Grundrechten einzuräumen, während er aber auch die Verpflichtungen dem Staat gegenüber und damit verbundenen Einschränkungen von Freiheiten definierte. ${ }^{53}$ Mit dieser Verfassung wurde ein totalitärer Staat geschaffen, denn der darin verankerte Grundsatz der Volksmacht stärkte die führende Rolle der Kommunistischen Partei in der sowjetischen Gesellschaft. Die Zeit nach der Verfassung von 1936 wurde in der sowjetischen Doktrin als Etappe „des siegenden Sozialismus“" genannt. ${ }^{54}$ Derzeit bezeichnen die Historiker diesen Zeitraum bis zum Tod Stalins im Jahre 1953 als totalitären Staatsterror gegen die eigenen Bürger.

Allerdings begann die Stärkung der staatlichen Rolle im Leben der sowjetischen Bürger bereits vor 1936 - und zwar mit Zwangsvereinigungen oder Kollektivierungen von Bauernwirtschaften zu Kolchosen, mit staatlichen Industrialisierungsplänen und umfassenden staatlichen Rechtsvorschriften im Bereich des Privatrechts. Bereits 1929 sprach man in den regierenden Kreisen von einer bemerkbar werdenden „Ehe- und Familienkrise“ der sowjetischen Gesellschaft. Obdachlose Kinder, sozial und wirtschaftlich ungeschützte Frauen oder der Rückgang der Geburtenrate waren objektive Gründe, die den Staat zwangen, nach neuen Lösungen zu suchen. Die Antwort war eine scharfe Änderung der Staatspolitik bezüglich der Ehe und Familie, die Abkehr vom Liberalismus, das heißt von der Freiheit in sexuellen Beziehungen und von den liberalen Formen der ehelichen Vereinigungen. Diese wurden als unethisch und der sowjetischen Moral unangemessen eingestuft, da sie die soziale Disziplin, soziale Konsolidierung, Mobilisierung und Kollektivierung gefährdeten, die im Einklang mit den Anforderungen des zukünftigen totalitären Staates ins Leben gerufen

51 OSIPOVA, S. Die Entwicklung der lettischen Rechtssprache nach der Gründung der Republik Lettland am Beispiel der juristischen Ausbildung. In: LUTS-SOOTAK, M. - OSIPOVA, S. - SCHÄFER, F. L. (Hg.). Einheit und Vielfalt in der Rechtsgeschichte im Ostseeraum. Frankfurt am Main, Berlin, Bern, Bruxelles, New York, Oxford, Wien: Peter Lang Verlag, 2012, S. 173-185.

52 POLLMANN, A. - LOHMANN, G. Menschenrechte: Ein interdisziplinäres Handbuch. Stuttgart - Weimar: J. B. Metzler, 2012, S. 114.

53 Конституция (Основной закон) СССР в редакции от 5 декабря 1936 г. [online]. [28. 9. 2018]. Verfügbar um: http://constitution.garant.ru/history/ussr-rsfsr/1936/red_1936/3958676/.

54 КОХАНОВА, Л. А. - АЛЕКСЕЕВА, Т. С. История Российской государственности. 4. Aufl. Москва: МГИУ, 2008, S. 310. 
wurden. ${ }^{55}$ Mit Verständnis der Beziehung zwischen der Entscheidung einer Frau, Kinder zu haben und sie zu erziehen, und einer stabilen Familie, enthielt das neu konzipierte Familienrecht die Idee einer stabilen, monogamen Familie, der wichtige öffentliche Aufgaben zukamen - eine neue Generation zu reproduzieren und verantwortliche junge sowjetische Bürger zu erziehen. „Die Familie erfüllt mit der menschlichen Fortpflanzung, die eine natürliche und eine ihrer wichtigsten Funktionen ist, die Funktionen der kommunistischen Erziehung junger Gesellschaftsmitgliedern und der Entwicklung ihrer Persönlichkeit sowie wichtige wirtschaftliche Funktionen, "56 schrieb J. Vēbers in der Doktrin des sowjetischen Familienrechts. Eine politisch treue, monogame Familie wurde zur ,grundlegenden Einheit der sowjetischen Gesellschaft" erklärt, und geriet somit in die Zuständigkeit der staatlichen Fürsorge und Überwachung. ${ }^{57}$ In dem Staat sprach man nicht mehr davon, dass die Familie im Kommunismus zusammen mit dem Staat und den Rechten gestorben wären, sondern von der Stärkung des Instituts der Familie als einer staatlich wichtigen Aufgabe. Diese Politikänderung war durch Verordnungen gekennzeichnet, zum Beispiel, der am 27. Juni 1936 verabschiedete Beschluss des Zentralen Exekutivkomitees der UdSSR „Über das Verbot von Abtreibungen, die Erhöhung materieller Hilfe für Gebärende, die staatlichen Beihilfen für Mehrkindfamilien, die Erhöhung der Anzahl von Entbindungskliniken, Kindertagesstätten und die Verbreitung des Kindergarten-Netzwerks, die Verstärkung der strafrechtlichen Haftung für die Nichtzahlung von Unterhalt und einige Änderungen im Ehescheidungsrecht" .58

Diese Verordnung leitete die Politik ein, die für den Sowjetstaat im Familienrecht eine Priorität blieb. Die während der Lenin-Zeit etablierte Freiheit von Frauen, sich für eine Abtreibung zu entscheiden, wurde auch abgeschafft. Die heutigen russischen Forscher vermuten, dass das Abtreibungsverbot mit den Plänen Stalins, ein mächtiges, dicht besiedeltes Land oder eine große Armee in der Zukunft zu schaffen, verbunden sein konnte. ${ }^{59}$ Das Abtreibungsverbot wurde in der UdSSR nur im Jahr 1955 aufgehoben.

In Sowjetlettland wurde das sowjetische Ehe- und Familienrecht in den 1940er Jahren in dieser konservativen Form eingeführt, in der sich der Staat sowohl zur Fürsorge für die Familie verpflichtete, als auch eine gewisse Kontrolle über diese ausübte. Die reale zivilrechtliche Gleichstellung der Geschlechter und die rechtliche Gleichstellung von Ehepartnern war in dieser Zeit für die lettische Gesellschaft eine Neuheit. Obwohl die lettischen Frauen ihre politische Gleichheit durch die Gründung der Republik Lettland im Jahre 1918 bereits erworben hatten, war jedoch der Ehemann das Familienhaupt auch nach dem

55 АНТИПОВА, op. cit.

56 VĒBERS, Latvijas PSR gimenes tiesības, s. 7.

57 СТАЙТС, Р. Женское освободительное движение в России. Феминизм, нигилизм и больиевизм. 1860-1930. Москва: "Российская политическая энциклопедия" (РОССПЭН), 2004, S. 522.

58 Постановление ЦИК СССР N 65, СНК СССР N 1134 от 27. 6. 1936 (извлечение) О запрещение абортов, увеличении материальной помощи роженицам,установлении государственной помощи многосемейным, расширении сети родильных домов, детских яслей и детских садов, усиления уголовного наказания за неплатёж алиментов и о некоторых изменениях в законодательстве о разводах. Собрание законов и распоряжений Рабоче-Крестьянского Правительства СССР, 1936, Bd. 34, S. 309.

59 ТОЛЬЦ, М. О советском опыте регулирования семейной жизни граждан. [online]. [20. 2. 2019]. Verfügbar um: http://www.gazeta.ru/comments/2014/07/22_x_6129129.shtml. 
neuen Zivilgesetzbuch von 1937, und die Gleichstellung der Geschlechter begann sich im Zivilrechts in Lettland erst zu entwickeln. ${ }^{60}$

Am 26. November 1940 wurde in der Lettischen SSR das Zivilgeseztbuch (ZGB) der Republik Lettland von 1937 außer Kraft gesetzt, und stattdessen trat das Gesetzbuch der RSFSR „Über die Ehe, Familie und Vormundschaft“ vom 19. November 1926 in Kraft. Gleichzeitig wurden die Standesämter reorganisiert, und die Registrierung des Zivilstandes wurde der Zuständigkeit der Kirche entnommen. ${ }^{61}$ Am 4. April 1941 wurden die Vormundschaftsbehörden reformiert. Diese Aufgaben wurden auf die Exekutivkomitees von Distrikt-, Stadt- und Gemeindeabgeordneten übertragen. ${ }^{62}$ Vorher waren Waisengerichte für diese Fragen zuständig. ${ }^{63}$ Wie der Professor des sowjetischen Familienrechts J. Vēbers feststellte: „Die Weiterentwicklung der Gesetzgebung des Familienrechts in Lettland [in der Lettischen SSR] ist nicht mehr von der Entwicklung der Gesetzgebung des ganzen sowjetischen Familienrechts zu trennen." 64

Während des Zweiten Weltkriegs, als Lettland unter der Besatzung des nationalsozialistischen Deutschlands stand (1941-1944), wurden in Sowjetrussland die Institution der Ehe und die staatliche Unterstützung für elternlose Kinder sowie Mütter gestärkt. Hier ist man eine Reihe von Dekreten zu nennen:

1. Mit dem Dekret vom 21. November 1941 wurde eine Kinderlosigkeitssteuer für kinderlose Bürger und Paare eingeführt. Männer mussten diese Steuer im Alter von 20 bis 50 Jahren und Frauen - von 20 bis 45 Jahren zahlen, falls sie keine Kinder hatten. ${ }^{65}$ Diese Steuergelder wurden für die staatliche Versorgung von Kriegswaisen und Unterstützung von Mehrkindfamilien vorgesehen. Die Kinderlosigkeitssteuer gab es unter verschiedenen Bedingungen auch im sowjetischen Steuersystem bis zum Zusammenbruch der Sowjetunion 1990/1991. Auch diese Steuer zeichnet die öffentliche Dimension des Lebens eines Sowjetbürgers aus: für die Kinderbetreuung ist die ganze Gesellschaft zuständig. Wenn eine Person keine Kinder hat, dann soll sie ihren finanziellen Beitrag für die Erziehung von Kindern leisten, die keine Eltern haben oder deren Eltern arm sind.

2. Das Dekret „Über die Adoption“ vom 8. September 1943 legte fest, dass die Adoptiveltern das Recht hatten, dem Kind ihren Namen zu geben. Bei Kindern über 10 Jahre war seine Zustimmung notwendig. Der neue Name des Kindes wurde in das Geburtenbuch registriert. 66

3. Das Dekret „Über die Erhöhung der staatlichen Unterstützung für Schwangere, Mehrkindmütter, alleinerziehende Mütter sowie die Einführung des Ehrentitels ,Mutter-Heldin', des Ordens von Mutter Ruhm und der Medaille ,Muttermedaille“" vom 8. Juli 1944. Durch dieses Dekret bezog sich die Kinderlosigkeitssteuer auch auf Eltern von

60 OSIPOVA, S. Sieviešu tiesības Latvijā 1918-1940: starp politisko pilntiesību un civiltiesisko nevienlīizzību. Latvijas Universitātes žurnāls Juridiskā zinātne, 2015, Bd. 8, S. 111-125.

61 VĒBERS, Gimenes tiesības, S. 19.

62 Ibidem.

63 Latvijas Republikas 2. 8. 1937. "Likums par pilsētu bāriṇtiesām”. Valdības Vēstnesis, 1934, Nr. 177, S. 1.

64 VĒBERS, Gimenes tiesības, S. 20.

65 Указ Президиума Верховного Совета СССР от 21 ноября 1941 года О налоге на холостяков, одиноких и бездетных граждан СССР. Ведомости Верховного Совета СССР, 1941, Nr. 42, S. 1, 2.

66 Указ Президиума Верховного Совета СССР от 8 сентября 1943 года Об усыновлении. Ведомости Верховного Совета СССР, 1943, Nr. 34, S. 1, 2. 
einem oder zwei Kindern. Allerdings gab es dabei unterschiedliche Steuersätze, und zwar 6\% vom Einkommen zahlten Kinderlose, 1\% Menschen mit einem Kind und $0,5 \%$ Eltern mit zwei Kindern. Im Gegenteil hat die Mutter von mindestens drei Kindern wesentliche Unterstützung erhalten. Das Dekret hob gleichzeitig das faktische Zusammenleben als der Eheformen auf, indem der Artikel 19 festgelegte, dass die gesetzlichen Rechte und Pflichten nur für eine faktische Ehe gelten. Das Dekret ermutigte faktisch zusammenlebende Personen zur Registrierung der Ehe unter Angabe der Dauer des faktischen Zusammenlebens. Der Artikel 20 hob das Recht von Müttern auf, die Vaterschaft gerichtlich feststellen zu lassen und Unterhalt von einem Mann zu verlangen, mit dem sie nicht verheiratet waren. Es wurde ein neues Konzept ,alleinerziehender Mutter" eingeführt. „Alleinerziehende Mutter“ war eine unverheiratete Mutter mit Kind(ern), dessen/deren Vaterschaft niemand anerkannt hat. Darüber hinaus wurde die Pflicht eingeführt, eine Ehe im Reisepass der Ehegatten zu registrieren. Für die Ehescheidung waren ausschließlich Volksgerichte zuständig, das Scheidungsverfahren war kompliziert. ${ }^{67}$ Das Gericht war bei dem Scheidungsverfahren verpflichtet, die Ehegatten zuerst zu versöhnen. Nur wenn das Gericht der ersten Instanz die Ehepartner nicht versöhnen konnte, hatte der Antragsteller das Recht, sich an das Gericht der zweiten Instanz zu wenden, wo der Fall in der Sache geprüft wurde. Dies fand in den Scheidungsstatistiken umgehend Niederschlag - im Jahre 1940 wurden in der UdSSR 205000 Ehen geschieden, 1945 waren es 31-mal weniger Ehescheidungen, nur noch 6 600. ${ }^{68}$ Unter dem Einfluss staatlicher Ideologie und der Tatsache, dass Informationen über Scheidungen in der lokalen Presse reflektiert wurden, wurden Eheleute, die sich für eine Scheidung entschieden hatten, öffentlich verurteilt und als unmoralisch anerkannt. Der Schuldige an der Scheidung (Ehebrecher oder Trunkenbold), wurde oft mit Ausschluss aus der Kommunistischen Partei bestraft. ${ }^{69}$

Die letzten Dekrete der Kriegszeit, die da Ehe- und Familienrecht geändert hatten, waren das Dekret „Über das Verfahren zur Anerkennung des eigentlichen Eheverhältnisses, wenn der Ehegatte im Krieg gefallen war oder vermisst ist" vom 10. November 1944 sowie das Dekret „Über die Anwendung des Dekrets des Präsidiums des Obersten Sowjets der UdSSR vom 8. Juli 1944 bezüglich Kinder, deren Eltern nicht in einer registirerten Ehe leben“70 vom 14. März 1945. Diese Dekrete ermöglichten denjenigen, die wegen der Kriegsumstände nicht in der Lage waren, die Anforderungen des Dekrets vom 8. Juli 1944 zu erfüllen und ihre Ehe registireren zu lassen, ihre Rechte sowie die ihrer Kinder zu verteidigen, das Erbe ihres im Krieg gefallenen Vaters zu beantragen.

67 Указ Президиума Верховного Совета СССР от 8 июля 1944 г. «Об увеличении государственной помощи беременным женщинам, многодетным и одиноким матерям, усилении охраны материнства и детства, об установлении почетного звания «Мать-героиня» и учреждении ордена «Материнская слава» и медали «Медаль материнства». Ведомости Верховного Совета СССР, 1944, Nr. 37, S. 1.

68 ТОЛЬЦ, op. cit.

69 КОЩЕЕВ, А. В. Расторжение брака по советскому законодательству. Вестник Вятского государственного гуманитарного университета, 2010, Nr. 4, S. 77.

70 Указ Президиума Верховного Совета СССР от 14 марта 1945 г. «О порядке применения Указа Президиума Верховного Совета СССР от 8 июля 1944 г. в отношении детей, родители которых не состоят между собой в зарегистрированном браке». Ведомости Верховного Совета СССР, 1945 , Nr. 15, S. $1,2$. 
Alle diese Änderungen wurden weitgehend durch den Krieg verursacht, wo eine große Mobilität von Menschen herrschte und stabile soziale Bindungen gelöst wurden. Deshalb war es schwierig, die Existenz eines tatsächlichen Zusammenlebens vor Gericht mit Zeugenaussagen zu beweisen, während viele Personen mehrere parallele Familien hatten. Es sei darauf hinzuweisen, dass die Bauern, die während der Kollektivierung gezwungen wurden, in den Kollektivbetrieben (in die Kolchosen) zu arbeiten, keinen Reisepass hatten. Den bekamen sie nur, wenn sie in den Krieg zogen Dementsprechend war es auch unmöglich, das Heimatdorf zu verlassen. Während des Krieges begann die „große Volkswanderung“, in deren Folge viele Männer in ihre Heimatdörfer nicht mehr zurückkehrten. Dies beeinträchtigte auch die Stabilität des Instituts der Familie. Im Gegensatz dazu zeichneten sich die Nachkriegsjahre in der UdSSR durch einen starken Anstieg von Eheschließungen aus, was einerseits der staatlichen Forderung nach einer registrierten Ehe, andererseits auch dem Friedensund der Rückkehr von Menschen nach langer Abwesenheit zu ihren Lieben geschuldet war. ${ }^{71}$

Die Ehescheidungsfreiheit wurde durch strenge staatliche Kontrolle eingeschränkt. ${ }^{72}$ Das sehr komplizierte und umständliche Scheidungsverfahren, in dem das Gericht die Scheidung ablehnen konnte, wenn es keine Rechtsgrundlage dafür sah, galt in der UdSSR 21 Jahre lang. Der Beschluss des Plenums des Obersten Gerichtshofs der UdSSR vom 16. September 1949, der Erläuterungen der für die Gerichte verbindlichen Rechtsvorschriften enthielt, legte fest, dass ein Gericht eine Ehe nicht scheiden darf, wenn die Gründe für die Scheidung den kommunistischen Moralprinzipien nicht entsprachen. Diese verbindlichen Erläuterungen wurden vom Plenum des Obersten Gerichtshofs der UdSSR 1969 annulliert. ${ }^{73}$ Eine leichtere Ehescheidung war ab dem 29. August 1946 nur in gesetzlich vorgeschriebenen Ausnahmefällen möglich, z.B. wenn einer der Ehegatten eine mehr als dreijährige Freiheitsstrafe zu verbüßen hatte, oder an einer chronischen unheilbaren psychischen Erkrankung litt. ${ }^{74}$

\section{Die Entwicklung des sowjetischen Ehe- und Familienrechts zwischen Stalins Tod 1953 und 1968/1969, als das letzte Gesetz des sowjetischen Ehe- und Familienrechts verabschiedet wurde}

Nach Stalins Tod im Jahre 1953 wurde die „strenge Hand des Staates“ in vielen rechtlichen Fragen gelockert. Dieser Zeitraum (1953-1964) zeichnete sich durch das sog. , Tauwetter“ der Leitung des ersten Sekretärs der KPdSU Nikita Chruschtschow aus. Dies wurde auf dem XX. Parteitag der KPdSU initiiert, auf dem N. Chruschtschow einen Bericht „Über den Personenkult und seine Folgen“ hielt. ${ }^{75}$ Die zur Zeit Stalins eingeführte staatliche Verwaltungspolitik und die Repressionen gegen die Bevölkerung wurden verurteilt, und

\footnotetext{
71 АРАЛОВЕЦ, Н. А. Городская семья в России, 1927-1959 г2. Тула: Гриф и К, 2009, S. 154, 155.

72 VĒBERS, Latvijas PSR gimenes tiesības, S. 13.

73 Пленум Верховного Суда СССР Постановление от 4 декабря 1969 года N. 10. “O практике применения судами основ законодательства Союза ССР и союзных республик о браке и семье”. [online]. [21. 2. 2019]. Verfügbar um: http://xn--b1azaj.xn--p1ai/USSR/postanovlenie-plenuma-vs-sssr /N10-ot-04.12.1969-sssr.html.

74 КОЩЕЕВ, op. cit., S. 77.

75 ХРУЩЁВ, Н. С. Доклад на ХХ съезде КПСС «О культе личности и его последствиях». Известия ЦК КПCC, 1989, Nr. 3, S. 1.
} 
der Kurs der staatlichen Politik wurde mit dem Ziel, das sozialistische Recht und seine rechtlichen Grundsätze, Demokratisierung, Bürgerrechte und Freiheiten wiederherzustellen, wesentlich geändert. ${ }^{76}$ Im Familienrecht machte sich das „Tauwetter“ in der von N. Chruschtschow geleiteten UdSSR jedoch nicht bemerkbar, weil die zur Zeit Stalins eingeführte Familienpolitik weiter praktiziert wurde und keine Rechtsvorschriften geändert wurden.

Das schwierige und erniedrigende Scheidungsverfahren blieb noch bis zur Zeit von Leonid Breschnew (1964-1982) aufrechterhalten, als das Dekret „Über einige Änderungen im Scheidungsverfahren vor Gerichten“ am 10. Dezember 1965 erlassen wurde. Mit diesem Dekret wurde die vorgeschriebene Veröffentlichung des Scheidungsverfahrens in der lokalen Zeitung und das zweistufige gerichtliche Scheidungsverfahren - das erste Gericht versöhnt, das zweite scheidet die Ehe - aufgehoben. Dementsprechend behandelte das Gericht künftig die Scheidungsverfahren in einer Instanz. ${ }^{77}$ Es waren aber nicht die letzten Änderungen im Ehe- und Familienrecht, da man in der UdSSR mit der Arbeit an neuen Gesetzbüchern des Ehe- und Familienrechts begann. In Moskau, im Zentrum der Union, wurden am 27. Juli 1968 vom Obersten Rat der UdSSR die Grundlagen des Ehe- und Familienrechts der UdSSR und anderer Sowjetrepubliken genehmigt. ${ }^{78}$ Die Sowjetrepubliken sollten bei der Erarbeitung ihrer Gesetzbücher die Leitlinien der Grundlagen befolgen.

Die neuen Grundlagen des Ehe- und Familienrechts vereinfachten in erster Linie das Scheidungsverfahren. Die neue Regelung legte fest, dass die Ehe vom Standesamt geschieden werden konnte, wenn die Ehegatten keine minderjährigen Kinder und keine Vermögensstreitigkeiten hatten. Eine solche Voraussetzung wurde auch von den Gesetzbüchern der Sowjetrepubliken übernommen, einschließlich des Gesetzbuchs der Lettischen SSR von 1969, das festlegte, dass die Ehe durch das Gericht geschieden wird. Aber in Fällen, „wenn sich die Ehegatten, die keine minderjährigen Kinder haben (Artikel 39), über die Ehescheidung einig“ oder „,bei der Scheidung der Ehe mit einer für vermisst oder handlungsunfähig erklärten Person, oder mit einer zu einer mindestens dreijährigen Freiheitsstrafe verurteilten Person“ (Art. 40), kann die Ehe vom Standesamt geschieden werden. Die Ehe wurde drei Monate nach der Einreichung des Antrags geschieden, um den Ehegatten noch eine Überlegunszeit zu gewähren. ${ }^{79}$

In der neuen Regelung wurde der Grundsatz der „,sowjetischen sozialen Gerechtigkeit“ noch stärker betont. So wurde z.B. die Regelung der Unterhaltsansprüche noch detaillierter erarbeitet. ${ }^{80}$ Daher sollten bestimmte Gesetzesvorschriften rückwirkend gelten. Eine rückwirkende Geltung betraf die rechtlichen Familienverhältnisse, die im Gesetzbuch von 1926 nicht reguliert wurden, ${ }^{81}$ z.B. die Erklärung einer Ehe für nichtig in Fällen, in denen die Ehe ohne Ziel, eine Familie zu gründen, geschlossen worden war, oder wenn

76 БИЮШКИНА, Н.И. Принципы советского права в контексте кодификации 1950-х-1960-х гг. Genesis: исторические исследования,. 2015, Nr. 6, S. 291-310.

77 О некоторых изменениях порядка рассмотрения в судах дел о расторжении бракаУказом Презириума Верховного Совета СССР от 10 декабря 1965 г. Ведомости Верховного Совета СССР, 1965, Nr. 49, S. 725.

78 Закон об утверждении основ законодательства СССР и союзных республик о браке и семье от 27 июня 1968. Ведомости Верховного Совета СССР, 1968, Nr. 27, S. 241.

79 VĒBERS, J. (Hg.) Latvijas PSR laulības un gimenes kodeksa komentāri. Rīga: Avots, 1985, S. 109.

80 БИЮШКИНА, op. cit., S. 291, 292.

81 VĒBERS, Gimenes tiesības, S. 27. 
die Voraussetzungen für die Eheschließung nicht erfüllt waren (d. h., heiraten durften nur ledige, volljährige, handlungsfähige Personen, die mit dem Ehepartner nicht eng verwandt waren, oder wenn dabei kein Adoptionsverhältnis bestand). ${ }^{82}$ Obwohl die vorher genannten Einschränkungen mit Ausnahme der rechtswidrigen Scheinehe in den sowjetischen Ehegesetzen bereits von Anfang an integriert waren und ein ganzer Abschnitt (Artikel 74 bis 84) des Gesetzbuchs von 1918 das Verfahren und die Grundlage, wann ein Gericht die Ehe für nichtig erklären konnte, ${ }^{83}$ beschrieb, legte das Gesetzbuch von 1926 jedoch keinen rechtlichen Mechanismus fest, eine solche rechtswidrige Ehe zu beenden. Es sah vor, dass die Ehe nur in zwei Fällen zu bestehen aufhörte - mit dem Tod eines der Ehepartner oder mit der Ehescheidung. ${ }^{84}$ Deshalb war die gerichtliche Erklärung der Ehe für nichtig eine Neuerung des sowjetischen Rechts im Gesetzbuch von 1968 im Vergleich zum Gesetzbuch von 1926.

Darüber hinaus wurde im Gesetzbuch von 1968 eine neue Grundlage für die Erklärung der Ehe für nichtig geschaffen, nämlich der Abschluss von Scheinehen oder Ehen ohne Absicht, eine Familie zu gründen. Die Scheinehen waren in der 2. Hälfte der 1960er Jahre in der sowjetischen Gesellschaft aus zwei Gründen aktuell:

1. Solche Ehen wurden geschlossen, weil der Sowjetstaat zu jener Zeit seinen Bürgern Wohnmöglichkeiten zur Verfügung stellte, was davon abhängig war, ob die Person alleinstehend oder verheiratet war. Ein Ehepaar hatte nämlich größere Aussichten auf eine separate Wohnung als auf ein Zimmer in einem Wohnheim oder einer Gemeinschaftswohnung (eine Gemeinschaftswohnung war im sowjetischen System etwas ähnliches wie eine Wohngemeinschaft, allerdings wurden die Mieter vom Staat ausgesucht, außerdem es gab keine Hoffnung die Wohnung zu wechseln).

2. Ein weiterer Grund für Scheinehen war damals die Erlaubnis für Juden, mit ihren Familien aus der UdSSR auszuwandern. ${ }^{85}$ Im Staat, der sich von der übrigen Welt mit dem „eisernen Vorhang“ abgeriegelt hatte und seinen Bürgern nicht auszureisen erlaubte, stellte eine Scheinehe mit einem Juden die einzige Möglichkeit dar, den Sowjetstaat zu verlassen.

Rückwirkend galten im Gesetzbuch von 1968 auch die Vorschriften bezüglich der Vaterschaftsfesstellung bei einem unehelichen Kind auf gemeinsamen Antrag beider Eltern durch das Standesamt, ${ }^{86}$ was vorher verboten war, und zwar mit dem Ziel, die Eltern zur Eheschließung zu motivieren. Obwohl das Sowjetrecht die Gleichstellung von Rechten außerehelicher und ehelicher Kinder durchsetzte, wurde jedoch der Status ,außereheliches Kind" beibehalten.

Im sowjetischen Familienrecht ergaben sich die elterlichen Rechte und Pflichten historisch aus der Herkunft des Kindes. Wenn die Vaterschaft bei einem Kind nicht festgestellt war, dann standen alle elterlichen Rechte und Pflichten der Mutter zu. Umgekehrt, wenn

82 VĒBERS (Hg.), Latvijas PSR laulības un gimenes kodeksa komentāri, S. 119-121.

83 Кодекс законов об актах гражданского состояния, Брачном, Семейном и Опекунском праве. Принят на сессии ВЦИК 16 сентября 1918 года. Собрание узаконений и распоряжений правительства за 1917-1918 г2. Управление делами Совнаркома СССР. Москва: Госюриздат, 1942, S. 1045-1074.

84 Кодекс законов о браке, семье и опеке РСФСР 1926 года.

85 КОНСТАНТИНОВ, В. Еврейское население бывшего СССР в ХХ веке: сочиально-демографический анализ. Иерусалим: Viacheslav Konstantinov, 2007, S. 257.

86 VĒBERS, Gimenes tiesības, S. 27, 28. 
die Vaterschaft beim Kind im Einklag mit dem Gesetz festgestellt war, erwarb auch der Vater die elterlichen Rechte und Pflichten. So ging aus den am 27. Juni 1968 vom Obersten Rat der UdSSR genehmigten gesetzlichen Grundlagen des Ehe- und Familienrecht für die UdSSR und andere Sowjetrepubliken, nämlich aus Art. 18 hervor, dass beide Elternteile die gleichen Rechte und Pflichten unabhängig davon hatten, ob sie verheiratet waren oder nicht, ob sie zusammen oder getrennt lebten. Diese Regelung wurde auch in die Gesetzbücher anderer Sowjetrepubliken, einschließlich Artikel 61 des Gesetzbuchs über die Ehe und Familie der Lettischen SSR übernommen. ${ }^{87}$ Theoretisch galt diese Vorschrift für alle Familienformen - unvollständige Familien, bei denen die Eltern nie zusammen gelebt hatten, und Familien, bei denen die Eltern zusammen lebten, sowie Familien, bei denen die Eltern nicht mehr zusammen lebten. Allerdings war die Idee, einen einheitlichen Rahmen für so unterschiedliche faktische Familienverhältnisse zu schaffen, zweifelhaft. Infolgedessen sah diese abstrakte Norm zwar eine formale Gleichheit vor, war aber in verschiedenen tatsächlichen Situationen nicht gleichermaßen anwendbar. Daher richteten sich die sowjetischen Gerichte in der Praxis trotz der im Gesetzbuch festgelegten formalen Gleichheit immer nach der tatsächlichen Realität, so dass meistens die Mutter das Sorgerecht erhielt, und legten einen Rechtsstreit unter Berücksichtigung der emotionalen Beziehungen zwischen Eltern und Kind bei. Der Wohnort des Kindes wurde im Allgemeinen bei der Mutter festgelegt. ${ }^{88}$ Bald nach der Verabschiedung der Grundlagen des Ehe- und Familienrechts der UdSSR am 4. Dezember 1969 erließ das Plenum des Obersten Gerichtshofs der UdSSR verbindliche Erklärungen zur Anwendung der Grundlagen und der in den Sowjetrepubliken verabschiedeten Gesetzbücher des Ehe- und Familienrechts. Darin wurde festgelegt, dass die gemeinsame Erziehung des Kindes nur dann möglich sei, wenn ,der Vater mit dem Kind und seiner Mutter zusammen lebt oder das Kind regelmäßig trifft und ihm seine elterliche Fürsorge zeigt" “. ${ }^{9}$

Der Grundsatz der sozialen Gerechtigkeit im Sinne des Sowjetrechts wurde auch bei der Unterhaltsfrage umgesetzt, indem der Unterhalt für minderjährige Kinder unter Berücksichtigung der Kinderanzahl und des Gehalts des Unterhaltspflichtigen proportional bestimmt wurde. Dies wurde bereits in dem am 27. Juni 1936 verabschiedeten Beschluss des Zentralen Exekutivkomitees der UdSSR „Über das Verbot von Abtreibungen, die Erhöhung von materieller Hilfe für Gebärende, staatliche Beihilfen für Mehrkindfamilien, die Erhöhung der Anzahl von Entbindungskliniken, Kindertagesstätten und die Verbreitung des Kindergarten-Netzwerks, die Verstärkung der strafrechtlichen Haftung für die Nichtzahlung des Unterhalts und einige Änderungen im Ehescheidungsrecht ${ }^{\star 90}$ festgelegt und auch weiter beibehalten. Die Unterhaltspflicht wurde gemäß den am 27. Juli 1968 vom Obersten Rat der UdSSR genehmigten Grundlagen des Ehe- und Familienrechts der UdSSR und der Sowjetrepubliken nicht nur auf minderjährige und arbeitsunfähige Kinder, arbeitsunfähige Eltern und Großeltern bezogen, sondern galt auch eine bestimmte Zeit nach der Ehescheidung für geschiedene arbeitsunfähige Ehegatten. Als Umsetzungsmechanismus

\footnotetext{
87 Latvijas PSR laulības un gimenes kodeksa komentāri, S. 158.

88 PĒLMANE, op. cit.

89 Пленум Верховного Суда СССР Постановление от 4 декабря 1969 года Nr. 10.

90 Постановление ЦИК СССР N 65, СНК СССР N 1134 om 27. 6. 1936.
} 
des Grundsatzes der sozialen Gerechtigkeit wurde auch die Kinderlosigkeitssteuer auf beibehalten, die im Jahr 1941 eingeführt wurde. ${ }^{91}$

Im Vergleich zum ersten Jahrzehnt des Sowjetrechts wurde allerdings die Selbstbestimmung der Familieangehörigen nicht vollständig wiederhergestellt, weil die Familie nicht nur eine staatliche Beihilfe erhielt, sondern es kamen ihr auch öffentlich wichtige Aufgaben zu. Der Artikel 1 des Gesetzbuchs des Ehe- und Familienrechts der Lettischen SSR beschrieb folgende „Aufgaben des Ehe- und Familienrechts der Lettischen SSR: die sowjetische Familie, die auf den Grundsätzen kommunistischer Moral beruht, weiter zu stärken, ... zu erreichen, dass Kinder in Familien im Einklang mit den Grundsätzen der sozialen Erziehung erzogen werden, indem bei ihnen die Treue zur Heimat und die kommunistische Arbeitseinstellung gefördert werden, und dass sie auf eine aktive Teilnahme an der Errichtung der kommunistischen Gesellschaft vorbereitet werden, dass die Interessen von Mutter und Kind mit allen Mitteln geschützt und jedem Kind eine glückliche Kindheit gewährleistet werden, dass gefährliche Überreste und Traditionen aus der Vergangenheit in den Familienbeziehungen beseitigt werden... “ Der Schutz der mütterlichen Rechte konnte zur Einschränkung der väterlichen Rechte führen. In der Doktrin des sowjetischen Familienrechts wurde erkannt, dass ,der Grundsatz der Gleichheit von Frauen und Männern die Notwendigkeit nicht ausschließt, einen eigenen Rechtsstatus für Frauen zu schaffen. Dies ist in der Regel notwendig, da die Frau-Mutter eine besondere Stellung in der Gesellschaft und in der Familie einnimmt." $" 92$

Die erklärten Ziele bestimmten zugleich den öffentlich-rechtlichen Charakter des Ehe- und Familienrechts sowie die staatliche und öffentliche Kontrolle der ehelichen Beziehungen. Die öffentliche Kontrolle wurde durch ein nichtstaatliches Gericht - das sog. Kameradschaftsgericht - umgesetzt, das in Arbeitskollektiven bei den Partei- und Komsomoltreffen gebildet wurde und über die Beziehungen von Ehegatten verhandeln konnte. Die staatliche Kontrolle war bereits im Gesetz eingebettet, z.B. durch die Bevollmächtigung des Staates, eine Ehe für nichtig zu erklären und zu erkennen, dass die Ehe ohne Absicht, eine Familie zu gründen, geschlossen wurde.

Die 1968/1969 etablierte Ordnung galt im sowjetischen Ehe- und Familienrecht mit geringfügigen Änderungen (Präzisierungen der Lettischen SSR von 1980 bezüglich der Vaterschaftsfeststellung, Ausschluss der Präambel nach der Wiederherstellung der Republik Lettland im Jahre 1992, wesentliche Änderungen des Artikels 1, wo die Treue zur Lettischen SSR durch die Treue zur Republik Lettland ersetzt wurde, ${ }^{93}$ sowie Änderungen zum Schutz der Kinderrechte ${ }^{94}$ ) bis zur Wiederherstellung der Unabhängigkeit der Republik Lettland und der Wiederherstellung des Zivilgesetzes am 1. September 1993. ${ }^{95}$

91 БИЮШКИНА, op. cit., S. 302-310.

92 VĒBERS, Latvijas PSR gimenes tiesības, S.13.

93 Latvijas Republikas Augstākās Padomes 1992. gada 14. janvāra likums Par grozījumiem un papildinājumiem Latvijas laulības un ǵimenes kodeksā. [online]. [10. 12. 2018]. Verfügbar um: http://m.likumi.lv /doc.php?id=72430.

94 Latvijas Republikas Augstākās Padomes 1992. gada 24. marta likums Par grozījumiem un papildinājumiem Latvijas laulības un gimenes kodeksā un citos kodeksos bērnu tiesību aizsardzības jomā. [online]. [10. 12. 2018]. Verfügbar um: http://likumi.lv/doc.php?id=65476.

95 Latvijas Republikas Augstākās Padomes 1993. gada 25. maija likums Par atjaunotā Latvijas Republikas 1937. gada Civillikuma gimenes tiesību dal̦as spēkā stāšanās laiku un piemērošanas 


\section{Zusammenfassung}

1. Bei der Entstehung des sowjetischen Ehe- und Familienrechts sowie seiner Entwicklung seit der bolschewistischen Revolution bis zur Zeit des stalinistischen Terrors ist Folgendes zu betonen:

a) Die Trennung von Kirche und Staat, die Anerkennung der Zivilehe als der einzigen, vom Staat faktischer Ehe, gleichzeitig Toleranz gegen die nicht verheirateten geschlechtlichen Beziehungen - diese waren neben einer einfachen Registirerung der Ehe und ihrer Scheidung außerordentlich liberale Tendenzen.

b) Die Anerkennung absoluter Gleichstellung von Geschlechtern nicht nur im öffentlichen, sondern auch im privaten Recht war ein progressiver, die sozialistischen Ideale umsetzender Schritt.

c) Die freie Entscheidung von Frauen für eine staatlich bezahlte Abtreibung.

d) Die rechtliche Gleichstellung aller Kinder unabhängig davon, ob sie ehelich oder außerehelich geboren wurden.

e) Die Einführung des Ehe- und Familienrechts als eines unabhängigen Rechtsbereiches.

f) Die Anerkennung die Legalität des faktischen Zusammenlebens als einer der Eheformen.

2. In Sowjetlettland wurde das sowjetische Ehe- und Familienrecht in den 1940er Jahren in seiner konservativsten Form des „Stalinismus“ eingeführt. Das sowjetische Familienrecht aus der Stalin-Zeit verzichtete auf die ursprünglich etablierte Gleichstellung aller Bürger ungeachtet ihrer Religion, ethnischer Herkunft im Ehe- und Familienrecht und insbesondere auf den Grundsatz der Gleichstellung von Frau und Mann innerhalb der Familienverhältnisse neben dem Liberalismus und dem Grundsatz von Nichteinmischung des Staates in das Familienleben. In der Staatspolitik und im Recht wurden dabei folgende Grundsätze gestärkt:

a) Der Grundsatz des staatlichen Schutzes der Familie, der mit dem Grundsatz der gesetzlichen Regelung der Familienverhältnisse durch den Staat eng verbunden war. Dies wurde nicht nur in den das Ehe- und Familienrecht regulierenden Gesetzen, sondern auch in den Verfassungen der UdSSR und der Lettischen SSR festgelegt.

b) Der Grundsatz des Interessenschutzes von Mutter und Kind, der ermöglichen sollte, die Kindererziehung und die Vollzeitbeschäftigung von Müttern durch staatliche Unterstützung zu vereinbaren.

c) Die gesellschaftliche Mitverantwortung für die Kindererziehung, einschließlich der Sicherung ihres Lebensunterhalts, was sich durch die Einführung der Kinderlosigkeitssteuer auszeichnete.

d) Im Eherecht wurden folgende Grundsätze verkündet: Monogamie, freiwillige Eheschließung, begrenzte Freiheit der Ehescheidung unter staatlicher Kontrolle.

3. Am 26. November 1940 wurde in der Lettischen SSR das Zivilgeseztbuch (ZGB) der Republik Lettland von 1937 außer Kraft gesetzt, und stattdessen trat das Gesetzbuch der RSFSR „Über die Ehe, Familie und Vormundschaft“ vom 19. November 1926 in Kraft. Die Weiterentwicklung der Gesetzgebung des Familienrechts in der Lettischen

kārtību. [online]. [10. 12. 2018]. Verfügbar um: http://likumi.lv/ta/id/57034-par-atjaunota-latvijas -republikas-1937-gada-civillikuma-gimene-tiesibu-dalas-speka-stasanas-laiku-un-kartibu. 
SSR ist nicht mehr von der Entwicklung der Gesetzgebung des ganzen sowjetischen Familienrechts zu trennen.

4. Nach Stalins Tod im Jahre 1953 lockerte sich die „strenge Hand des Staates“ in vielen rechtlichen Fragen. Im Familienrecht machte sich jedoch das „Tauwetter“ in der von N. Chruschtschow geleiteten UdSSR (1953-1964) nicht bemerkbar, weil die zur Zeit Stalins eingeführte Familienpolitik weiter praktiziert wurde und keine Rechtsvorschriften geändert wurden. Das schwierige Scheidungsverfahren blieb bis zur Zeit von L. Breschnew (1964-1982) erhalten, als das Dekret „Über einige Änderungen im Scheidungsverfahren vor Gerichten“ am 10. Dezember 1965 erlassen wurde.

5. In den Schlussfolgerungen über die Neuerungen im sowjetischen Ehe- und Familienrecht im Zeitraum zwischen 1953 und 1970 ist festzustellen, dass die persönliche Freiheit, die zu Zeiten des Stalin-Personenkults eingeschränkt war, nun teilweise wiederhergestellt wurde, da Abtreibungen wieder erlaubt wurden, die Ehescheidung und die Vaterschaftsfeststellung bei einem unehelichen Kind vereinfacht wurden. Gleichzeitig hat sich dieser Rechtsbereich wesentlich weiterentwickelt in den „Grundlagen des Ehe- und Familienrechts der UdSSR und der Sowjetrepubliken“ von 1968 sowie im Gesetzbuch des Ehe- und Familienrechts der Lettischen SSR von 1969 juristisch vollständiger und detaillierter definiert. 